\title{
A Comparative Study of Goldblatt's English Translation of Mo Yan's "The Republic of Wine"*
}

\author{
Hui Guo \\ School of Foreign Language, Qingdao University of Science \& Technology, China
}

\begin{abstract}
This article compares the original work of "The Republic of Wine" with Howard Goldblatt's translation, and finds that Mr. Goldblatt strives to find a balance between fidelity and betrayal, and adopts more methods of transliteration and literal translation, which makes translation into a cross-cultural communication. Also, this article focuses on exploring the translator's handling of culturally loaded words in the original work, and also provides new ideas and inspiration for Chinese-English translators. At the same time, "The Republic of Wine" is all-encompassing and contains a lot of metaphors; this paper analyzes the metaphor translation strategies in its English translation in order to provide some reference points for metaphor translation.
\end{abstract}

Index Terms - translation strategies, addition and deletion, rewrite, culturally loaded words

\section{INTRODUCTION}

Cultural studies have become a trend in the academic field, and cultural translation also plays an extremely important role in international cultural exchanges. The common cultural heritage of mankind around the world can only be enjoyed when translated into different languages. China is one of the ancient civilizations, and the extensive and profound Chinese traditional culture is looked up to by the whole world. To make China go to the world, English translation of Chinese traditional culture is an indispensable task.

Literature is the product and carrier of culture. Mo Yan's hometown of Shandong belongs to the Qilu cultural region. His works are not only full of rich Chinese cultural traditions, but also a lot of unique folk and secular culture. His works are rated as the richest "Chinese culture". Another important factor for Mo Yan's successful overseas communication is "good translation". The English translator of Mo Yan's works Howard Goldblatt, who is the well-known translator, also the highest-ranking Chinese literary translator in the English world. Among the many works translated by Howard Goldblatt, the English translation of "The Republic of Wine" was republished several times from 2000 to 2011 in Europe countries and it was widely praised by Western readers. "The Republic of Wine" shows the earth-shaking changes in China's officialdom over the past half a century. The content reflects the typical Chinese lifestyle and conversational thoughts. Chinese cultural elements run through the entire text of the novel. Howard Goldblatt's English translation greatly promoted the cultural exchanges between China and foreign countries and the spread of Chinese culture.

This article selects some examples from the original work and Howard Goldblatt's English translation. It studies and compares the differences between the two and concludes relevant translation strategies. It also examines Howard Goldblatt's translation methods for the original culturally loaded words in the translation process and explores Howard Goldblatt's translation style.

\section{HowARD GOLDBLATT'S TRANSLATION STRATEGIES FOR “THE REPUBLIC OF WinE”}

\section{A. Appropriate Use of Rewriting Strategies}

Western readers like to think about questions from a logical point of view, so Howard Goldblatt rewrites a long series of short limericks into logical and smooth English sentences. Mo Yan's works are described in details, and Chinese readers are used to this, but English readers are not accustomed to these words. Howard Goldblatt rewrites this so that the expression of the words is natural, unobstructed and concise, and it reads more like a work written by him than a translation.

For example:

“有朝一日我碰上他, 一定要和他展开一场血腥大辩论, 我要驳得他哑口无言噤若寒蝉, 然后还要揍他一顿, 让这个小子七空流血鼻青脸肿魂飞魄散一佛出世二佛涅槃。”

"I ever met him, I tell you, he's in for the verbal fight of his life."

\section{B. Reasonable Handling of Parallel Structures}

In Mo Yan's works, there are many parallel structures and most of them create momentum and ironic feeling. The

\footnotetext{
${ }^{*}$ Note: This article is the research result of the 2017 Foreign Language Teaching and Research Press Project. (Project number: 2017112301)
} 
words are vivid but difficult to translate. If these structures are all translated into English, then the corresponding English will be an unusually long sentence. Therefore, Howard Goldblatt chooses to omit most of the parallel structure and keep its most basic meaning in accordance with the English writing habit.

For example:

“我要像当年的您一样, 卧新尝苦胆、双眼冒金星, 头县梁、雉刺股, 拿起笔、当刀枪, 宁可死, 不退却, 不 成功, 便成仁。”

"I want to be just like you were then: sleeping on brushwood and eating gall, sparks leaping from your eyes, using your pen as a weapon, preferring death over dishonor."

In this parallel structure, there are too many idioms and allusions, and their connotations are similar to each other and have the same meaning. Howard Goldblatt rewrites the idioms and allusions in the original text into concise and clear sentences to help English readers understand it.

\section{Flexible Translation of the Ancient Chinese Poems}

A large number of ancient poems and famous sentences exist in Chinese works. The literal translation will make the target language readers feel puzzled. Mo Yan also quoted some ancient poems in "The Republic of Wine". Howard Goldblatt's translation strategy is not to directly translate the original meaning of the poems, but directly into the drink-urging words on the context.

For example:

“人生得意须尽欢。”

“Anybody who doesn't drink doesn't deserve to be called a man."

This is the verse of Li Bai, a poet of the Tang Dynasty, which means that people must enjoy joy in the world. In "The Republic of Wine", they are drink-urging words. Howard Goldblatt understood its meaning and translated it into a word to persuade wine.

\section{Explain Unique Cultural Terms}

Language is the carrier of culture, and words are the most basic unit of language. There are many unique vocabulary expressions in Chinese. For example, in Chinese medicine, there are many terms. In order to achieve the goal of cultural exchange, it is necessary to explain these cultural terms. As can be seen from the following example, in addition to rewriting paragraphs well, Howard Goldblatt can also consider carefully when translating Chinese medical terminology to make it easy for readers in the target language to understand.

For example:

“我慌忙往她的身上泼了一桶凉水，用一根生锈的铁钉子扎她的人中，扎她的虎口...”

"I hurriedly slashed a bucket of cool water over her and pricked the area between her nose and upper lip and the spot between her thumb and index finger with a rusty nail."

"Renzhong" and "tiger mouth" are unique Chinese terms. In traditional Chinese medicine, they refer to the two acupoints of the human body. Howard Goldblatt gave a clear explanation, making it easy for readers in the target language who know nothing about it, but know the body parts they refer to.

\section{E. Correctly Interpret Common Words}

In Chinese, some commonly used words are spoken in different tones in different situations, with different meanings and expressive effects. If it is translated into the same English word consistently, it will not express the effect that the original text should have. For example, the common Chinese word "Laozi" can refer to "I" in addition to "father". When "Laozi" refers to "I", it is an arrogant and lacking education method. In the following three example sentences, it can be seen that Howard Goldblatt has rewritten appropriately according to different contexts, not only in the same situation, but also in the tone of voice.

For example:

“听老子说。”

"Listen to what your sire has to say。”

“二等? 他妈的, 你们欺负老子!

"Second-grade? You're trying to cheat me, damn you!"

“...喝道: 兔崽子, 你敢骂老子? 老子皆了你! ”

“and roared, You bastard, who the hell do you think you're talking to? You're dead meat!"

By enumerating and comparing Chinese and English versions, it introduces the differences between Chinese and English cultures and the reading interest of English readers, and guides college students to master cross-cultural knowledge.

\section{The Translation Strategies of Culturally LoAded Words in Howard Goldblatt's EnGLiSh Version}

Culture-loaded words refer to words that best reflect the cultural information carried by language and reflect human social life in the language system. The culturally loaded words studied in this paper are words or phrases that contain 
unique aesthetic information in Chinese culture. Howard Goldblatt once mentioned that a good translation must first be "faithful", which means form equivalence and pragmatic function equivalence between the translation and the original. In the process of translating Mo Yan's work "The Republic of Wine" into English, he used literal translation. Literal translation with annotations, deletions and rewriting makes the translation and the original text achieves the equivalent of form and pragmatic function to meet the reading expectations of the target language readers, so as to achieve "faithful" reproduction of the original text. The following will explain Howard Goldblatt's translation strategies of dealing with culturally loaded words in details by listing examples in "The Republic of Wine".

\section{A. Literal Translation}

In literary works, culturally loaded words usually cannot find the corresponding appropriate expression in the target language, but there is a faithful requirement for translation to transmit the source language cultural information to the target language readers as much as possible. It is found that for the processing of culturally loaded words, Howard Goldblatt often uses literal translation to better retain the original style and faithfully convey the original flavor, so as to meet the readers' expectation of reading and the purpose of cultural exchange.

\section{B. Literal Translation with Annotation}

For culturally loaded words with obscure meanings, sometimes literal translation is difficult for the target language readers to understand directly. The translator often adopts the literal translation with annotation to explain the profound meaning of the culturally loaded words, ensuring that the original and target information are equal. It enables readers of the target language to understand the translation in a semantically coherent way, without causing any discomfort in meaning and form.

For example:

“他哼哼哼地奸笑一会, 道: 那姓莫的小子其实不姓莫, 他本姓管, 自吹是管仲的七十八代孙, 其实是狗屁不 沾边。他现在成了什么作家, 牛皮哄哄, 自以为了不起其实呀, 他那点老底儿我全知道。”

"With a sinister heh heh heh, he said, Mo is not the real family name of that rascal Mo Yan, you know. His real family name is Guan, which makes him the seventy-eighty descendant of Guan Zhong, Prime Minister of the scale of Qi during the Warring States Period, or so he claims. In fact, that's pure bullshit. A writer, you say? To listen to him, you'd think he was some sort of literary genius. Well, I know everything there is to know about him."

(Mo Yan, <The Republic of Wine>, P178)

The translator of this sentence adopts the method of literal translation and annotation, adding "Prime" after the word "Guan Zhong". "Minister of the state of Qi during the Warring States period" not only conveys a Chinese-style name to readers, but also translates the unique historical and cultural meaning of the name (thinkers in the Warring States Period in China) for readers in the target language. In addition, the "姓莫的小子" is specifically translated as "rascal Mo Yan" in the translation, clearly pointing out that "Mo"' is not simply translated as "Mo Yan" to avoid the misunderstanding of the third persona for the readers.

\section{Deletion}

When dealing with culturally loaded words that are slightly unfamiliar to the target readers, Howard Goldblatt boldly adopted deletion to make the translation more coherent. This is also in line with the coherence principle of teleology, that is, the translation must meet the requirements of intra-textual coherence, which is based on the relationship between the translation and the culture of the target language.

For example:

“有朝一日我碰上他, 一定要和他展开一场血腥大辩论, 我要驳得他哑口无言噤若寒蝉, 然后好要揍他一顿让 这个小子七穹流血鼻青脸肿魂飞魄散一佛出世二佛涅槃。”

"If I ever meet him, I tell you, he's in for the verbal fight of his life."

(Mo Yan, <The Republic of Wine >, P53)

In the translation here, the original sentence "我要驳得他亚口无言噤若寒蝉, 然后还要揍他一顿让这个小子七空 流血鼻青脸肿魂飞魄散一佛出世二佛涅槃" was completely deleted and untranslated. Howard Goldblatt attaches great importance to readers' reading effects. In order to meet the needs of publishers and target readers, and to cater to the aesthetic habits of Western readers, with the consent of the original author, he deletes the parts that may hinder readers' acceptance in order to meet the reading expectations of target language readers. If each culturally loaded word is translated one by one in the translation, it will make the translation difficult to understand and impair the fluency and coherence of the translation. Therefore, it is quite necessary for the translator to delete the places that hinder the reader's reading and comprehension without translating it to ensure the coherence of the translation.

\section{Addition and Deletion}

In the translation process, sometimes in order to ensure the continuity of the translation, the translator may add information while deleting some cultural information. The ultimate goal of this seemingly unfaithful approach is to facilitate the reading and comprehension of the target language readers. Whether it is deletion or addition, the goal is to ensure the consistency, readability and acceptability of the translation. 
For example:

“您的论断等于给我喝了一杯定心酒, 就像李玉和被鸠山逮捕前喝了李奶奶的那杯酒一样。”

"Your judgement would be my liquor of assurance, serving the same purpose as that glass of liquor the martyred hero Li Yuhe took from Aunt Li just before he was arrested."

(Mo Yan, <The Republic of Wine >, P23)

$\mathrm{Li}$ Yuhe, Hatoyama, and Granny Li are all characters in the classic Chinese model drama "Red Lantern" in the 1970s. For Chinese readers who are familiar with model dramas, especially those who have experienced the Cultural Revolution, the relationship between these three characters is clear. After the Communist hero Li Yuhe drank Grandma Li's wine, he was quickly arrested by the captain of the Japanese gendarmerie Hatoyama, and finally died heroically. However, if the same explicit means is used in the translation, the information it provides cannot be related to the cognitive environment of the target reader. During the translation process, the translator simply translates the message "being arrested by Hatoyama" into "before he was arrested", omitting the historical figure "Hatoyama", which is not important and is slightly unfamiliar to readers in the target language, through the word "martyred" added as an attributive to modify "hero", so that the target reader can infer the development of the character's fate based on semantics, which not only achieves the same contextual effect effectively avoids the reader's excessive cognitive effort and ensures the coherence of the translation, readability and acceptability.

\section{E. Rewrite}

Due to the differences between the Chinese and English language systems, it is inevitable that the translator needs to properly convert or recreate the source language during the translation process, so that the translated language is more in line with the reading habits of the target language readers. This translation process can also be understood as rewriting for the purpose to achieve "meaning faithfulness". In order to achieve "meaning faithfulness", the translator abandons the language form of the source language to ensure the fluency and readability of the translation.

For example:

“老师您是我名副其实、货真价实的老师, 我发现您不但是写小说的行家里手, 而且, 您还是品酒的大内高手。”

"Sir, you are indeed my true, my genuine, mentor, for not only are you a master novelist, but you know your way around a liquor bottle."

(Mo Yan, < The Republic of Wine >, P90)

In the sentence, "大内高手" refers to the martial artist who is responsible for guards in the imperial palace. The text expresses the superb level of wine tasting. The translator's free translation is "you know your way around a liquor bottle. This seemingly "betrayal" rewriting method actually conforms to the principle of loyalty. Howard Goldblatt, through rewriting, gets rid of the shackles of the language form to achieve the faithful meaning of the source language, so that the translation better conforms to English expression habits and is better understood by target language readers.

\section{Metaphor Translation Strategies From The Perspective of Relevance Translation TheORY}

In the process of metaphor translation, translator must know to what extent he wants to be consistent with the metaphor in the original text. The translator also needs to consider the cognitive language environment of the target language readers, and reshape the metaphorical image in the translation according to the meaning of the metaphor in the original text, so as to ensure that the translation and the original metaphor form the best correlation effect. The metaphor translation strategies used by Howard Goldblatt are as follows.

\section{A. Simile}

Metaphor is a kind of hidden metaphor. Translated signs such as "being", "becoming" and "becoming" are used as metaphors between the body and the vehicle. In some metaphors in China and the West, the cognitive environment is the same and the language form are similar, and when the literal translation is unreasonable or complicated, the simile method can be used to effectively achieve the best correlation.

For example:

“任何想压制新生力量的反动分子，都是的“螳臂挡车，不自量力”。”

"Any reactionary who thinks he can suppress a rising force is the same as "the mantis that tried to stop the ongoing wagon, a tragic overrating of one's abilities."

For example:

“丁钩儿感叹万分, 方知自己是井底之蛙, 知识贫乏。”

"With a sigh, Ding Gou'er realized how impoverished his knowledge was, like the proverbial frog at the bottom of a well."

In the examples, the "螳臂挡车" means that the mantis uses its front legs to block the car from moving forward. It is a metaphor of overpowering oneself and doing something that cannot be done. In this metaphor, the author compares the actions of reactionaries to suppress the new forces as the action of holding a car with an arm. The translator adds the simile sign word "the same", which is translated ingeniously and vividly, maximizing the style of the source language and what it conveys." With the information retained, the translation achieves the best reproduction of the original text. 
Readers of the target language can easily infer the author's communicative intentions based on the following "a tragic overrating of one's abilities." Also "丁钩儿" is "ontology," "井底之蛙" is "metaphorical objects", and "知识贫乏" is "basic metaphor". The translator not only retains the above three, but also adds the simile symbol "like" ", making the target languages more acceptable.

\section{B. Retaining Metaphors and Adding Metaphorical Meaning}

In order to preserve the image of the metaphorical objects as much as possible, the literal translation method is adopted. Due to the influence of social and cultural factors, some metaphorical objects have obvious national cultural characteristics or implicit historical events, characters, allusions, etc., which are difficult for the target readers to understand. When translating this kind of metaphor, you can add its metaphorical meaning after the literal translation, so that the metaphorical form of the original language can be preserved, and the reader can understand its meaning well.

For example:

“您这些话犹如醍灌顶，使我顿开茅塞。正是:打开两扇顶门骨，一桶茅台浇下来。”

"Those refreshing words filled my head with the clarified butter of great wisdom, removed all obstacles to understanding. Truly it was a case of: 'Open the gates of the throat."'

"醍醐灌顶" refers to pouring pure ghee on the top of the head, which is a metaphor for instilling Buddhist doctrine or wisdom into people to make them fully awakened. Howard Goldblatt translated it as "filled my head with the clarified butter of great wisdom", which not only retained the image of "醍醐", but also added "of great wisdom" to modify "醍 醐", supplementing its meaning and achieving the best relevance of the translation, so that readers of the translation with less processing effort can obtain sufficient context effects understanding.

\section{Free Translation}

Due to the significant differences between Chinese and Western cultures, languages, and social environments, a series of concepts and images in Chinese cannot be well conveyed to Western readers through literal translation. In order to achieve the best relevance, translators should be flexible and abandon the superficial literal meaning. Focusing on the interpretation of the original author's communicative intentions, free translation is used to translate the metaphorical and implicit meanings, so as to reproduce the original author's communicative intentions in a specific context.

For example:

“我搞得是绝对的高尔基和鲁迅式的严肃文学, 严格恪守着“革命现实主义和革命浪漫主义相结合”的不二法 门, 从不敢偷越雷池半步。”

"I work only on serious literature in the style of Gorki and Lu Xun; strictly following the one and only true method of 'combining revolutionary realism with evolutionary romanticism,' I have not taken a single wayward step, not once."

"不二法门" is a term used in Buddhism. Buddhism has many disciplines, and the Doctrine of Non-duality is the highest state. Since Western readers have little understanding of Buddhism, literal translation will make readers make unnecessary processing efforts, and the communicative intention of the original author is to let readers understand the meaning of this metaphor, so the translator translates it into "the one and only true method". This enables the target reader to deduce the original author's intention from the target text without having to pay too much processing effort, achieves the original author's intention, and matches the target reader's expectation.

\section{CONCLUSION}

This article compares the original work of "The Republic of Wine" with Howard Goldblatt's translation, and finds that Mr. Howard Goldblatt strives to find a balance between fidelity and betrayal, and adopts more methods of transliteration and literal translation, which makes translation into a cross-cultural communication. It also analyzes the metaphor translation strategies in its English translation in order to provide some reference points for metaphor translation. At the same time, this article focuses on exploring the translator's handling of culturally loaded words in the original work, also provides new ideas and inspiration for Chinese-English translators. Howard Goldblatt made the translation as much as possible to retain Chinese cultural characteristics and conform to English expression habits, and adopted methods such as deletion, addition, and rewriting to ensure the fluency, coherence and readability of the translation. After processing the information of the original text, Howard Goldblatt selectively transmitted to the target language readers, so as to realize the cultural interaction function of translation.

\section{REFERENCES}

[1] Goldblatt, Howard. (2012). The Republic of Wine. New York: Arcade Publishing.

[2] Goldblatt, Howard. (2012). The Republic of Wine. USA: Arcade Publishing.

[3] Mo Yan. (2012). The Republic of Wine. Shanghai: Shanghai Literature and Art Publishing House.

[4] Nida Eugene. (1993). Language, Culture and Translating. Shanghai: Shanghai Foreign Language Education Press.

[5] Shuttleworth, Mark \& Moira Cowie. (2005). Dictionary of Translation Studies. Beijing: Foreign Language Teaching and Research Press. 
[6] Shao Lu. (2011). A Study on the English Translation of Mo Yan's Novels. Shanghai: Chinese Comparative Literature.

Hui Guo was born in Harbin, China in 1978. She received her M.A. degree in linguistics from Northeast Forestry University, China in 2003. She is currently an associate professor in Qingdao University of Science \&Technology, Qingdao, China. Her research interests include linguistics and translation. She is a member of the Qingdao Translation Association. 